\title{
Pleurotus ostreatus and Trametes versicolor, Fungal Strains as Remedy for Recalcitrant Pharmaceuticals Removal Current Knowledge and Future Perspectives
}

\author{
Marcelina Jureczko* and Wioletta Przystaś \\ Environmental Biotechnology Department, the Silesian University of Technology, Poland
}

Received: March 08, 2018; Published: April 03, 2018

*Corresponding author: Marcelina Jureczko, Environmental Biotechnology Department, Faculty of Energy and Environmental Engineering, The Silesian University of Technology, Krzywoustego 8 St., 44-100 Gliwice, Poland, Tel: 4832237 29 18; Email: marcelina.jureczko@polsl.pl

\begin{abstract}
The consumption of pharmacologically active substances (PhACs) is steadily increasing. According to their recalcitrant nature and low biodegradability in wastewater treatment plants (WWTPs), they occur in rivers, lakes, and even ground and drinking waters. Because of that PhACs are considered to be emerging pollutants. Therefore new technologies which can be used to degrade them are investigated. Two white-rot fungi (WRF) strains: Pleurotus ostreatus and Trametes versicolor show quite good PhACs removal values. Broad applications of active and inactivated form of biomass are possible due to different mechanisms of their action, such as biodegradation by extracellular and intercellular enzymes or biosorption. Thus, the versatility for applying fungi, represent that this microorganisms are a promising tool to deal with problem of pharmaceutical compounds elimination from the environment. In this work has been also presented future possibilities, like their application in waste water and sludge treatment or future perspectives of removal of different group of pharmaceuticals by this promising and environmentally friendly technology
\end{abstract}

Keywords: Biosorption; Biodegradation; Fungi; Pharmaceuticals; Pleurotus ostreatus; Trametes versicolor

Abbreviations: ABTS: 2,2-azino-bis-(3-ethylbenzthiazoline-6-sulfonic acid); HOBT: Hydr Oxy Benzo Triazole; MnPs: Manganese-Dependent Peroxidases ; PhACs: Pharmacologically Active Substances; STPs: Sewage Treatment Plants; WRF: White-Rot Fungi; WWTPs: Waste Water Treatment Plants

\section{Introduction}

The consumption of pharmacologically active substances (PhACs) is steadily increasing, up to thousands of tons per year [1-3]. Unfortunatelygreatamountofthemcannotbeeasilyremoved through the conventional technologies used in wastewater treatment plants (WWTPs) [3-5]. Their recalcitrant nature cause their occurrence, as unmetabolized substances or as active metabolites in $\mathrm{ng} / \mathrm{l}$ or $\mu \mathrm{g} / \mathrm{l}$ in rivers, lakes, and even ground and drinking waters $[1,4-6]$. Because of that PhACs are considered to be emerging pollutants $[1,4,6]$. Even if their concentrations in water bodies are three to four orders of magnitude lower than those required producing pharmacological effects, bioaccumulation and biomagnification processes may occur [1]. The quality of aquatic environment has also the potential adverse effects on human health [7]. In addition, although risk for acute toxic effects for both fauna and flora is unlikely, chronic environmental toxic effects cannot be excluded $[1,4]$.
Because of that new technologies which can be used to degraded pharmaceuticals are investigated [3]. Fungal treatment of wastewaters has been pointed out as a promising technology for pharmaceutical remediation processes $[3,8,9]$. White-rot fungi (WRF), which belong to basidiomycetes, have a vast range of the unspecific enzymatic systems, and are capable of degrading different groups of xenobiotic compounds at very low concentrations $[3,4,10$ 12]. Besides living cells mechanism, which involves enzymes that cause biodegradation, also biosorption both on activated and inactivated biomass take part in recalcitrant pollutants elimination $[8,9]$. Two of the most promising fungal strains, which show quite good PhACs removal values, are Pleurotus ostreatus and Trametes versicolor. They are able to eliminate wide range of pharmaceuticals such as $\beta$-blockers (atenolol), antiepileptic (carbamazepine), analgesic (ibuprofen), anti-inflammatory (ketoprofen and naproxen) and estrogens (17 $\alpha$-ethynylestradiol), which suggests 
the feasibility of this group of microorganisms for pharmaceuticals bioremediation purposes $[5,11,13]$.

\section{Pharmaceuticals Removal by Pleurotus ostreatus and Trametes versicolor}

Even though elimination of many pharmaceuticals in conventional sewage treatment plants (STPs), due to their hydrophilicity, persistent nature, and the relativelylow concentration is more difficult than that of other organic pollutants, white-rot fungi show great potential in removal of these chemical compounds [14]. In (Table 1) it has been set together Pleurotus ostreatus and Trametes versicolor ability to remove pharmaceuticals, with the role of sorption and enzymatic mechanisms. While analyzing different studies it is important to keep in mind, that each experiment had its own specific methodology. Percentage of degradation could depend from medium where the trial was conducted and time of experiment. For example, Pleurotus ostreatus completely remove the synthetic hormone $17 \alpha$-ethinylestradiol (in concentration 200 $\mu \mathrm{g}$ ) in 3 days from a liquid complex or in 14 days from mineral medium [15]. Sometimes it could cause limitation of fungal ability to remove specific pharmaceutic. In Palli et al. [5] research atenolol degradation was negligible $(<20 \%)$ during the first 20 days but it increased up to $60 \%$ after notable biomass growth $130 \%$ when compared to the initial inoculum) of P. ostreatus.

Table 1: Pleurotus ostreatus, Trametes versicolor and their enzymes ability to remove pharmaceuticals.

\begin{tabular}{|c|c|c|c|c|c|c|c|}
\hline \multirow{3}{*}{ pharmaceutical } & \multicolumn{4}{|c|}{ Fungal Strain } & \multicolumn{3}{|c|}{ Enzyme } \\
\hline & \multicolumn{2}{|c|}{ Pleurotus ostreatus } & \multicolumn{2}{|c|}{ Trametes Versicolor } & \multirow{2}{*}{ laccase } & \multirow{2}{*}{$\begin{array}{c}\text { Cytochrome } \\
\text { P450 }\end{array}$} & \multirow{2}{*}{ MnPs } \\
\hline & Biodegradation & Sorption & Biodegradation & Sorption & & & \\
\hline 10,11-epoxycarbamazepine & - & - & $100^{[23]}$ & - & - & - & - \\
\hline $17 \alpha$-ethynylestradiol & $100^{[7,15]}$ & $19^{[7]}$ & - & - & $97.100^{[8,16]}$ & - & $>99^{[16]}$ \\
\hline 17b-estradiol 17-acetate & - & - & $>80^{[18]}$ & $>80^{[18]}$ & - & - & - \\
\hline Acetaminophen & - & - & $100^{[23]}$ & - & - & - & - \\
\hline Acridon & $0-60^{[5]}$ & - & $100^{[23]}$ & - & - & - & - \\
\hline Atenolol & $68-100^{[4,16]}$ & - & - & - & $100^{[5]}$ & $0^{[5]}$ & - \\
\hline Carbamazepine & - & - & $<30-98^{[3,6,14,29]}$ & $6-17^{[3,9,14]}$ & $5-37^{[14,16]}$ & p.r. ${ }^{[26]}$ & $14.20^{[16]}$ \\
\hline Ciprofloxacin & $55^{[4]}$ & - & $>90^{[21]}$ & - & $16^{[21]}$ & p.r. ${ }^{[21]}$ & - \\
\hline Clarithromycin & - & - & - & - & - & - & - \\
\hline Clofebric acid & - & - & $<30-97^{[14,18,29]}$ & $12.5^{[14]}$ & $7-20^{[14,16]}$ & p.r. ${ }^{[29]}$ & $<10^{[16]}$ \\
\hline Codiene & - & - & $100^{[23]}$ & - & - & - & - \\
\hline Citalopram & $100^{[5]}$ & $30^{[5]}$ & $100^{[23]}$ & - & - & - & - \\
\hline Diclofenac & - & - & $54-100^{[3,6,14]}$ & $10-80^{[3,5,6,14]}$ & $90-100^{[5,14,16]}$ & p.r. ${ }^{[5,14]}$ & $100^{[16]}$ \\
\hline Erythromycin & - & - & $100^{[23]}$ & - & - & - & - \\
\hline Fenoprofen & - & - & $100^{[14]}$ & $7^{[14]}$ & $20^{[14]}$ & - & p.r. ${ }^{[16]}$ \\
\hline gemfibrozil & $50^{[5]}$ & - & $83^{[14]}$ & $17^{[14]}$ & $20-30^{[14,16]}$ & p.r. ${ }^{[18]}$ & $30^{[16]}$ \\
\hline Ketoprofen & - & - & $<30-100^{[14,17,18]}$ & $0-15^{[5,14,17]}$ & $0-50^{[5,14,18]}$ & p.r. ${ }^{[5,17]}$ & $22^{[16]}$ \\
\hline Iopromide & - & - & $39-46^{[3]}$ & $1-8^{[3]}$ & - & - & - \\
\hline Ibuprofen & - & - & $100^{[4,14,29]}$ & $17^{[14]}$ & $<5-40^{[14,16,18]}$ & p.r. ${ }^{[18]}$ & $20^{[16]}$ \\
\hline Indomethacin & - & - & $100^{[14]}$ & $15^{[14]}$ & $>90^{[14]}$ & - & p.r. ${ }^{[16]}$ \\
\hline Metonidazol & - & - & $100^{[23]}$ & - & - & - & - \\
\hline Naproxen & - & - & $31-100^{[13,14,22]}$ & $12.5-23.7^{[14,22]}$ & $10-100^{[16,22]}$ & $100^{[22]}$ & $95^{[16]}$ \\
\hline Norfloxacin & - & - & $>90^{[21]}$ & - & $16.3^{[21]}$ & p.r. ${ }^{[21]}$ & - \\
\hline Prophenazine & - & - & $64^{[14]}$ & $10^{[14]}$ & $7^{[14]}$ & - & - \\
\hline Sulfamethazine & - & - & $>95^{[27]}$ & $25^{[27]}$ & $22^{[27]}$ & p.r. ${ }^{[27]}$ & - \\
\hline Sulfapyridine & - & - & $100^{[19]}$ & neg. ${ }^{[19]}$ & $75-98^{[19]}$ & - & - \\
\hline Sulfathiazole & - & - & $100^{[19]}$ & $17^{[19]}$ & $82-100^{[19]}$ & p.r. ${ }^{[19]}$ & - \\
\hline Venlafaxine & - & - & $49-53^{[3]}$ & $2-6^{[3]}$ & - & - & - \\
\hline
\end{tabular}

Note: p. r. - potential role, neg. - negligible role, no data

So atenolol is degraded by the fungus, but it requires a long contact time and high levels of biomass production [5]. As mentioned above biomass, but also pharmaceutic concentration is not without significance. As an example $94 \%$ of carbamazepine with initial concentration $9 \mathrm{mg} / \mathrm{L}$ have been removed when treated by $T$. versicolor for 6 days, but only $61 \%$ of the contaminant was degraded, when initial amount was $50 \mathrm{mg} / \mathrm{L}$ [9]. It sometimes cause difficulties in comparing result from different researches, 
like those above with $68 \%$ removing of carbmazepine in 7 days treated with $P$. ostreatus, when the input value was $4 \mu \mathrm{g} / \mathrm{L}$ [4]. Interestingly even the method of result evaluation has the influence on the outcome. It was found $64 \%$ of degradation of diclofenac treated with T. versicolor when the reduction was measured directly (with pharmaceutical concentration in both liquid and biomass), and only $54 \%$ when was measured indirectly (by subtracting the degradation value measured in the liquid from the killed control culture from the degradation measured in the liquid from the experimental culture from the batch experiments with fungi and spiked synthetic medium) [3].

\section{Role of Sorption}

Removal mechanisms during treatment with WRF include: sorption on the fungal biomass, degradation by extracellular enzymes, and degradation by mycelium bound or intercellular enzymes [16]. In case of pharmaceuticals overall elimination by fungi the contribution of sorption, fast, reversible and energyindependent process, cannot be neglected [3,17]. It gathers both absorption (entry of pollutants inside the biomass) and adsorption (adhesion of pollutants to the biomass surface). It depends on fungus, because specific interactions between PhACs and the surface components of each fungus can occur. The differences also take place, while sorption is on the active or inactive (killed) biomass [3]. Structure of biomass, and therefore their sorption capacities, may change according to the inactivation mechanism $[3,11]$. In active biomass, transport in living cells may play an important role $[3,8]$. In addition, biodegradation processes of absorbed compounds can occur in the active biomass due to intracellular enzymes [3]. On the other hand metabolically active biomass, may suppressed toxic pollutants by cellular protective mechanisms [8].

What is more, way of biomass inactivation can have influence on sorption. These presents Palli et al. [5] research, where heatkilled biomass of T. versicolor remove $47 \%$ of diclofenac and $15 \%$ of ketoprofen, but these percentages were reduced to $10 \%$ and $0 \%$, respectively, when sodium azide was used to inactivate biomass, by blocking active transport across membrane or vesicular pathways [5]. Not without significance is chemical character of pollutants. In Nguyen et al. [18] it has been reported high (60-99\%) removal of hydrophobic compounds, to which belongs naproxen or ibuprofen by the live culture, but relatively low by the inactivated one, which indicates biodegradation was the main mechanism. Hydrophilic one on the other hand showed negligible removal by both active and inactivated culture, which may indicate the importance of sorption in subsequent degradation by the whole-cell [18]. The biosorption mechanisms are classified to different types on the basis of cell metabolism status or pollutants sorption location [8], and have been presented at (Figure 1). The drawback of sorption is that fungal biomass after treatment might be considered as a potential waste, which requires appropriate treatment before being released into the environment [3].

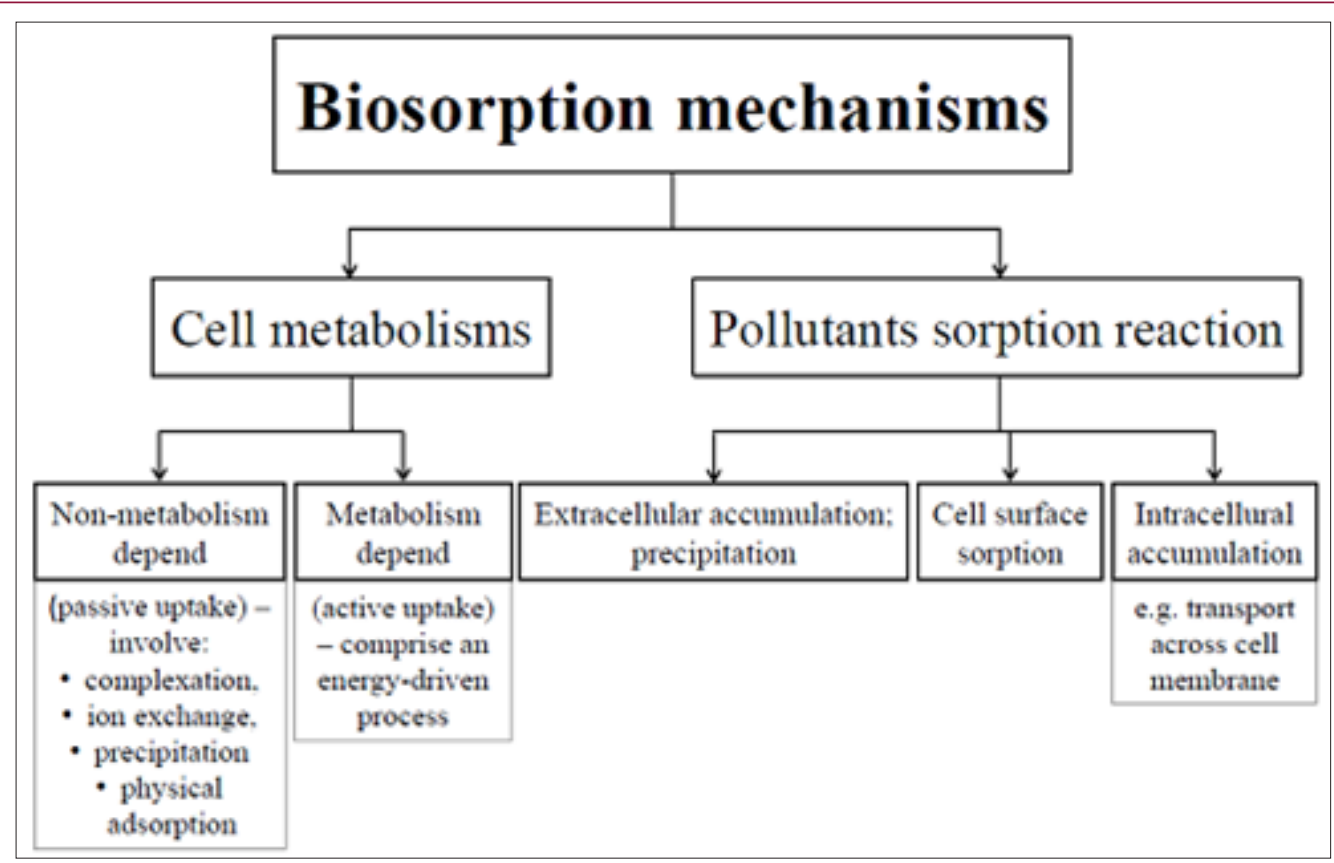

Figure 1: The biosorption mechanisms classified to different types on the basis of cell metabolism status or pollutants sorption location after $\mathrm{Lu}$.

\section{Enzymes Contribution in Pharmaceuticals Degradation}

Biodegradation by whole-cell can be due to intracellular (cytochrome P450), extracellular (laccase, manganese-dependent peroxidases - MnPs), mycelium-associated enzymes and their synergetic effects $[1,5,16,18,19]$. This can lead to significant differences in removal by whole cell WRF and harvested enzyme. For example carbamazepine removal by $P$. ostreatus is $100 \%$, by
T. versicolor $98 \%$, whereas crude and purified laccase could only achieve 5-37\% removal. Similarly, ibuprofen was completely removed by whole-cell WRF, while its removal by crude and purified laccase was in the range of 5-40\%. It substantiates the role of mycelium bound and/or intercellular enzymes [16]. Indeed, the role of cytochrome P450 in the degradation of naproxen, diclofenac, and carbamazepine has been demonstrated is studies where those 
pharmaceuticals were only partially removed (15-50\%) in the presence of cytochrome P450 inhibitor $[9,11,16,20]$.

What is more there are significant differences depending on the origin of the enzymes. Almost complete removal of three pharmaceuticals: diclofenac, ibuprofen, and naproxen, have been achieved after treatment with crude enzyme extracted from $T$. versicolor, whereas purified laccase from this fungi strain achieved only $20-50 \%$ removal [16]. To similar conclusions on the efficacy dependence from the origin of the enzyme have come Tran et al. [14] with researches with T. versicolor, cell-free extract (crude laccase), and commercial laccase, examined on diclofenac and naproxen [14]. On the other hand purified laccases are more effective for the removal of phenolic compounds and usually ranges from 70 to 99\%. Even though that for most non-phenolic compounds removal by crude enzyme is $<20 \%$, it's worth to mention that relatively higher removal of diclofenac (40-50\%), and ibuprofen (30-45\%), has been reported because these compounds contain both electron donating and electron withdrawing functional groups [16].

Not without significance is also enzyme activity, like in Nguyen et al. [18] work, where when laccase activity increase from 2 to 6 $\mathrm{U} / \mathrm{mL}$, reported removal of naproxen changed from 30 to $100 \%$, ibuprofen from 10 to $40 \%$ and from 25 to $50 \%$ in case of ketoprofen [18]. What is more, sometimes there is a need for mediator, like in Prieto et al. [21] researches, when in in vitro assays with purified laccase after adding enzyme mediator ABTS - 2,2-azino-bis-(3ethylbenzthiazoline-6-sulfonic acid) diammonium salt, norfloxacin and ciprofloxacin removal increased from $0 \%$ to $33.7 \%$ and from $16.3 \%$ to $97.7 \%$ respectively [21]. Also carbamazepine degradation by purified laccase increased from $0 \%$ to $60 \%$ after addition of a redox mediator HOBT (hydroxybenzotriazole) in Jelic et al. [9] work or naproxen from $10 \%$ to $95 \%$, what was presented in MarcoUrrea et al. [11,13,17,20,22,23] article [9,22,23].

\section{Current and Future Possibilities of Pleurotus ostreatus and Trametes versicolor Use}

Pleurotus ostreatus and Trametes versicolor use for removing pharmaceuticals is one of the most promising bioremediation systems, because these WRF are well known as producers of nonspecific enzymes, which allow to simultaneous attack complex mixtures of pollutants $[1,9,22]$. In addition preconditioning of fungal strains to particular pollutants is not require, because part of the enzymes useful in the degradation are produced constitutively while others after induction by nutrient limitation [1,22]. Because of that they could find application in wastewater and sludge treatment.

\section{Waste Water Treatment Application}

There have been conducted several studies about $P$. ostreatus and T. versicolor wastewater treatment application [5]. Unfortunately, researches presented by Cruz-Morató et al. [23] showed that in fluidized bed bioreactor inoculated with T. versicolor biomass used for urban wastewater treatment in non-sterile conditions pharmaceuticals removal can change. When comparing with the removal in sterile conditions some drugs elimination such as acetaminophen, ibuprofen, citalopram was the same $(100 \%)$, some like ketoprofen increased (from $35 \%$ in sterile to $100 \%$ in non-sterile), and some, like in case of 10,11-epoxycarbamazepine decreased (from $100 \%$ in sterilized urban wastewater to $79 \%$ in non-sterilized) [23]. Also Yang et al. [24] proved that diclofenac removal by T. versicolor in membrane bioreactor (MBR) efficiency decrease from $100 \%$ in sterile conditions to $55 \%$ in non-sterile [24]. Even though white-rot fungi capacity to successful degradation of pharmaceuticals is irrefutable the problems while application in real urban wastewater occur. They are: continuous fungal and their extracellular enzymes washout in continuous flow reactors, contaminants mixtures, PhACs low concentrations and mentioned before non-sterile environment [23,24]. Bacterial contamination affects adversely on removal efficiency, because of: competition between bacteria and fungi for substrate; fungal mycelium damaging, biomass growth disrupting and destabilization of fungal activity $[16,24]$. Some of the strategies to avoid bacterial contamination are:

a. Coagulation-flocculation pretreatment of wastewater, which will reduce the initial bacterial count;

b. Coupling bioreactor with micro-screen, which would retain fungal biomass but allow the washout of bacteria with effluent:

c. Immobilization of fungal strains onto different carriers;

d. Operation under acidic $\mathrm{pH}$, according to fact that optimum $\mathrm{pH}$ for the growth fungi is lower than that preferable for most of bacteria;

e. Periodic fungi biomass replacement;

f. Use of disinfecting agents (like ozone), which will selectively inactivate bacteria but will not impose any harmful effects on fungal biomass.

In case of enzymatic reactors where enzymes instead of wholecell WRFs are used, limitation are washout of the enzyme and mediators. To avoid it could be use:

a. Coupling of enzymatic reactor with a membrane with suitable pore size;

b. Enzymes immobilization [16].

These possibilities enable the implementation of technology using the WRF, and minimizing inconvenience. It is worth to mention, that had been proved that, besides pharmaceuticals removal, P. ostreatus is able to reduce chemical oxygen demand of the hospital wastewater which is an important advantage [5].

\section{Sludge Treatment}

WRF might be applied not only at wastewater treatment plant itself, but also in elimination pharmaceuticals form sludge. Bio solids may still contain significant amounts of drugs and currently the development of alternative strategies for its treatment is a matter of concern $[10,11]$. Fungi are robust organisms and are more tolerant to high concentrations of contaminants than bacteria [10]. The 
Rodríguez-Rodríguez et al. $[13,19,26]$ researches results suggest that a fungal treatment with $T$. versicolor could be a promising process $[11,13]$. His another researches $(2011)$ of pharmaceuticals biodegradation by this fungi in sterilized sewage sludge under solidphase conditions demonstrate complete removal of phenazone, bezafibrate, fenofibrate, cimetidine, clarithromycin, sulfamethazine and atenolol after treatment, while seven others pharmaceuticals were removed between $42 \%$ and $80 \%$ [25]. In his another work (2012) presented T. versicolor in a sludge-bioslurry reactor, when fifteen out of 24 detected pharmaceuticals were removed at efficiencies over $50 \%$ after the treatment (such as diclofenac, ibuprofen, indomethacine, sulfamethazine, sulfathiazole), including eight completely degraded (e. g. sulfapyridine) [26].

What is more García-Galán et al. [27] demonstrated degradation capacity of T. versicolor in sterilized sewage sludge, where $100 \%$ removal was accomplished for sulfapyridine and sulfathiazole [27]. Also Palli et al. [5] evidenced carbamazepine degradation by $P$. ostreatus in solid state fermentation [5]. In addition both Aydin [10] and Rodríguez-Rodríguez et al. [25,27] researches showed significant reduction in toxicity of sludge, which contain pharmaceuticals after treatment with T. versicolor [10,25]. It all demonstrating the potential application of the fungus for sewage sludge bioremediation $[27,28]$.

\section{Future Possibilities}

On the base of presented knowledge have been tested tolerance of Pleurotus ostreatus and Trametes versicolor to anticancer drug bleomycin. Pure cultures of selected microorganisms were isolated with tissue method from fruit bodies and propagated. Their ability to grow in the presence of selected substance, were conducted by placing $8 \mathrm{~mm}$ fungi disc on solid media (Malt Extract Agar) with addition of two different concentrations of chosen cytostatic $(1 \mathrm{mg} / \mathrm{L}$ and $4 \mathrm{mg} / \mathrm{L})$ and incubating for five days in $26^{\circ} \mathrm{C}$. Test have been conducted in five repetitions. Their tolerance was designated by growth ability presented in cm (diameter of colony), which show (Figure 2). Even though, growth inhibition is noticeable, both fungal strains are able to growth in quiet high bleomycin concentrations, which may induce that those strains will find use also in removing this cytostatic drug, but further researches are require.

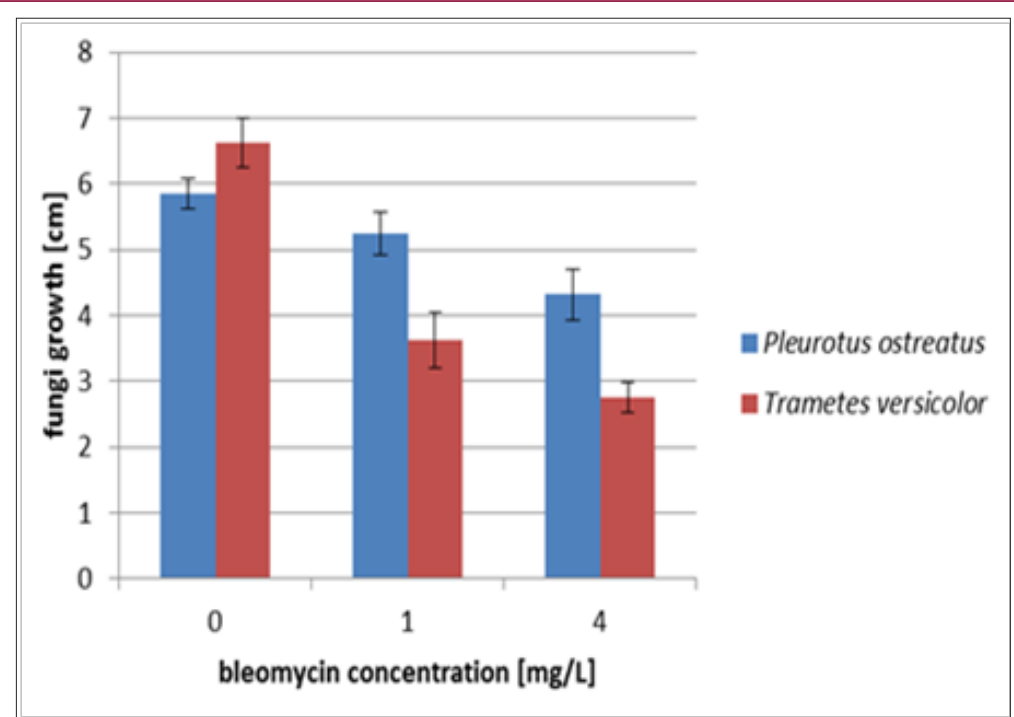

Figure 2: Pleurotus ostreatus and Trametes versicolor growth in the presence of bleomycin in concentration $1 \mathrm{and} 4 \mathrm{mg} / \mathrm{L}$.

\section{Conclusion}

Using white-rot fungi: Pleurotus ostreatus and Trametes versicolor in pharmaceuticals removal is a promising and environmentally friendly technology. Broad applications of both active and inactivated form are possible due to different mechanisms of their action, such as biodegradation by extracellular and intercellular enzymes or biosorption. In addition there is also a possibility of using only their extracellular enzymes. Thus, the versatility for applying fungi, represent that this microorganisms are a promising tool to deal with problem of pharmaceutical compounds elimination from the environment.

\section{References}

1. Buchicchio A, Bianco G, Sofo A, Masi S, Caniani D (2016) Biodegradation of carbamazepine and clarithromycin by Trichoderma harzianum and Pleurotus ostreatus investigated by liquid chromatography - highresolution tandem mass spectrometry (FTICR MS-IRMPD). Science of the Total Environment 557-558: 733-739.
2. Ji C, Hou J, Wang K, Zhang Y, Chen V (2016) Biocatalytic degradation of carbamazepine with immobilized laccase-mediator membrane hybrid reactor. Journal of Membrane Science 502: 11-20

3. Lucas D, Castellet Rovira F, Villagrasa M, Badia Fabregat M, Barceló D, et al. (2018) The role of sorption processes in the removal of pharmaceuticals by fungal treatment of wastewater. Science of the Total Environment 610-611: 1147-1153.

4. Rodarte Morales AI, Feijoo G, Moreira MT, Lema JM (2011) Degradation of selected pharmaceutical and personal care products (PPCPs) by white-rot fungi. World J Microbiol Biotechnol 27(8): 1839-1846.

5. Palli L, Castellet Rovira F, Péerez Trujillo M, Caniani D, Sarrá Adroguer M, et al. (2017) Preliminary Evaluation of Pleurotus ostreatus for the Removal of Selected Pharmaceuticals from Hospital Wastewater. Biotechnol Prog 33(6): 1529-1537.

6. Rodríguez Rodríguez CE, Jelić A, Pereira MA, Sousa DZ, Petrović M, et al. (2012) Bioaugmentation of Sewage Sludge with Trametes versicolor in Solid-Phase Biopiles Produces Degradation of Pharmaceuticals and Affects Microbial Communities. Environ Sci Technol 46 (21): 1201212020. 
7. Santos IJ S, Grossman MJ, Sartoratto A, Ponezi AN, Durrant LR (2012) Degradation of the Recalcitrant Pharmaceuticals Carbamazepine and $17 \alpha$-Ethinylestradiol by Ligninolytic Fungi. Chemical Engineering Transactions 27: 169-174.

8. Lu T, Zhang QL, Yao SJ (2016) Application of Biosorption and Biodegradation Functions of Fungi in Wastewater and Sludge Treatment In: Purchase D. (eds) Fungal Applications in Sustainable Environmental Biotechnology. Fungal Biology. Springer International Publishing, Cham, Switzerland 2016: 65-90.

9. Jelic A, Cruz Morató C, Marco Urrea E, Sarrà M, Perez S, et al. (2012) Degradation of carbamazepine by Trametes versicolor in an air pulsed fluidized bed bioreactor and identification of intermediates, Water research 46(4): $955-964$.

10. Aydin S (2016) Enhanced biodegradation of antibiotic combinations via the sequential treatment of the sludge resulting from pharmaceutical wastewater treatment using white-rot fungi Trametes versicolor and Bjerkandera adusta. Appl Microbiol Biotechnol 100(14): 6491-6499.

11. Marco Urrea E, Pérez Trujillo M, Cruz Morató C, Caminal G, Vicent T (2010) Degradation of the drug sodium diclofenac by Trametes versicolor pellets and identification of some intermediates by NMR. Journal of Hazardous Materials 176(1-3): 836-842.

12. Tortella G, Durán N, Rubilar 0, Parada M, Diez MC (2015) Are whiterot fungi a real biotechnological option for the improvement of environmental health? Critical Reviews in Biotechnology 35(2): 165172.

13. Rodríguez Rodríguez CE, Marco Urrea M, Caminal G (2010) Naproxen degradation test to monitor Trametes versicolor activity in solid-state bioremediation processes, Journal of Hazardous Materials 179(1-3): 1152-1155.

14. Tran NH, Urase T, Kusakabe O (2010) Biodegradation Characteristics of Pharmaceutical Substances by Whole Fungal Culture Trametes versicolor and its Laccase. Journal of Water and Environment Technology 8(2): 125-140.

15. Křesinová Z, Moeder M, Ezechiáš M, Svobodová K, Cajthaml T (2012) Mechanistic Study of $17 \alpha$-Ethinylestradiol Biodegradation by Pleurotus ostreatus: Tracking of Extracelullar and Intracelullar Degradation Mechanisms. Environ Sci Technol 46(24): 13377-13385.

16. Asif MB, Hai FI, Singh L, Price WE, Nghiem LD (2017) Degradation of Pharmaceuticals and Personal Care Products by White-Rot Fungi-a Critical Review. Current Pollution Reports 3(2): 88-103.

17. Marco Urrea E, Pérez Trujillo M, Cruz Morató C, Caminal G, Vicent $\mathrm{T}$ (2010) White-rot fungus-mediated degradation of the analgesic ketoprofen and identification of intermediates by HPLC-DAD-MS and NMR. Chemosphere 78 (4): 474-481.

18. Nguyen LN, Hai FI, Yang S, Kang J, Leusch FD L, et al. (2014) Removal of pharmaceuticals, steroid hormones, phytoestrogens, UV-filters, industrial chemicals and pesticides by Trametes versicolor: Role of biosorption and biodegradation. International Biodeterioration \& Biodegradation 88: 169-175.

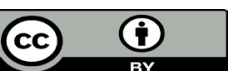

This work is licensed under Creative Commons Attribution 4.0 License

Submission Link: https://biomedres.us/submit-manuscript.php
19. Rodríguez Rodríguez CE, García Galán MJ, Blánquez P, Díaz Cruz MS, Barceló D, et al. (2012) Continuous degradation of a mixture of sulfonamides by Trametes versicolor and identification of metabolites from sulfapyridine and sulfathiazole. Journal of Hazardous Materials 213-214: $347-354$

20. Golan Rozen N, Chefetz B, Ben Ari J, Geva J, Hadar Y (2011) Transformation of the Recalcitrant Pharmaceutical Compound Carbamazepine by Pleurotus ostreatus: Role of Cytochrome P450 Monooxygenase and Manganese Peroxidase. Environ Sci Techno 45 (16): 6800-6805.

21. Prieto A, Möder M, Rodil R, Adrian L, Marco Urrea E (2011) Degradation of the antibiotics norfloxacin and ciprofloxacin by a white-rot fungus and identification of degradation products. Bioresource Technology 102(23):10987-10995.

22. Marco Urrea E, Pérez Trujillo M, Blánquez P, Vicent T, Caminal G (2010) Biodegradation of the analgesic naproxen by Trametes versicolor and identification of intermediates using HPLC-DAD-MS and NMR Bioresource Technology 101(7): 2159-2166.

23. Cruz Morató C, Ferrando Climent L, Rodriguez Mozaz S, Barceló D, Marco Urrea E, et al. (2013) Degradation of pharmaceuticals in non-sterile urban wastewater by Trametes versicolor in a fluidized bed bioreactor. Water research 47(14): 5200-5210.

24. Yang S, Hai FI, Nghiem LD, Nguyen LN, Roddick F, et al. (2013) Removal of bisphenol A and diclofenac by a novel fungal membrane bioreactor operated under non-sterile conditions. International Biodeterioration \& Biodegradation 85: 483-490.

25. Rodríguez Rodríguez CE, Jelic A, Llorca M, Farré M, Caminal G, et al. (2011) Solid-phase treatment with the fungus Trametes versicolor substantially reduces pharmaceutical concentrations and toxicity from sewage sludge. Bioresource Technology 102(10): 5602-5608.

26. Rodríguez Rodríguez CE, Barón E, Gago Ferrero P, Jelic A, Llorca M, et al. (2012) Removal of pharmaceuticals, polybrominated flame retardants and UV-filters from sludge by the fungus Trametes versicolor in bioslurry reactor. Journal of Hazardous Materials 233-234: 235-243.

27. García Galán MJ, Rodríguez Rodríguez CE, Vicent T, Caminal G,Díaz Cruz MS, et al. (2011) Biodegradation of sulfamethazine by Trametes versicolor: Removal from sewage sludge and identification of intermediate products by UPLC-QqTOF-MS. Science of the Total Environment 409(24): 5505-5512.

28. Rodriguez Rodriguez CE, Marco Urrea E, Caminal G (2010) Degradation of naproxen and carbamazepine in spiked sludge by slurry and solidphase Trametes versicolor systems. Bioresource Technology 101(7): 2259-2266.

29. Marco Urrea E, Pérez Trujillo M, Vicent T, Caminal G (2009) Ability of white-rot fungi to remove selected pharmaceuticals and identification of degradation products of ibuprofen by Trametes versicolor. Chemosphere 74(6): 765-772

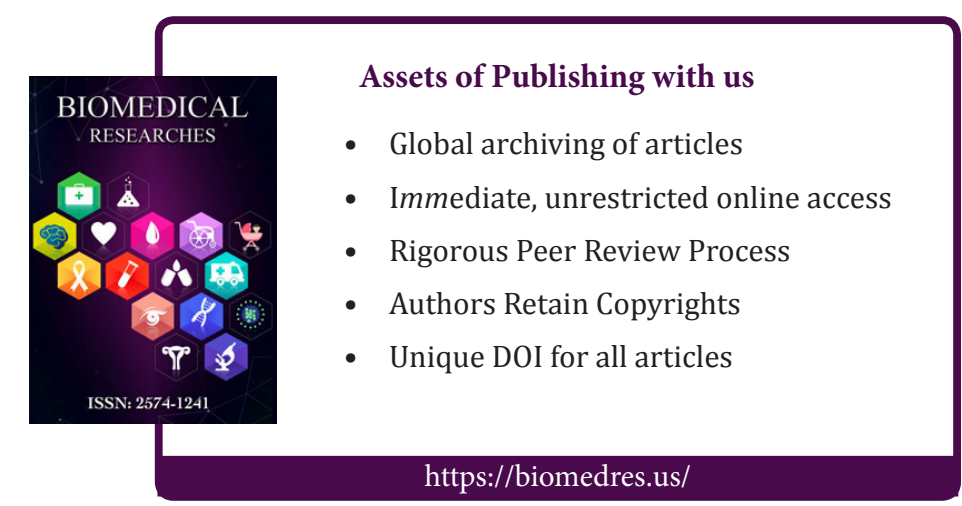

